\title{
A Case of Multiple Sclerosis to Gabon: Myth or Reality!
}

\author{
Ibrahima Aissata Camara', Lansana Laho Diallo², Philomène Kouna Ndouongo ${ }^{1}$ \\ ${ }^{1}$ Service of Neurology of the CHUL, Libreville, Gabon \\ ${ }^{2}$ Service of Neurology of the CHU Kipé, Conakry, Guinea \\ Email: ibrahaissata@yahoo.fr
}

How to cite this paper: Camara, I.A., Diallo, L.L. and Kouna Ndouongo, P. (2019) A Case of Multiple Sclerosis to Gabon: Myth or Reality! Open Access Library Journal, 6: e5592.

https://doi.org/10.4236/oalib.1105592

Received: July 9, 2019

Accepted: August 4, 2019

Published: August 7, 2019

Copyright $\odot 2019$ by author(s) and Open Access Library Inc.

This work is licensed under the Creative Commons Attribution International License (CC BY 4.0).

http://creativecommons.org/licenses/by/4.0/

\begin{abstract}
Introduction: Multiple sclerosis is a neuro-inflammatory demyelinating disease rare in Africa south of the Sahara. Objective: The objective of this work is to describe multiple sclerosis in African black women from Gabon and to list the principles of care. Observation: We report the case of a Gabonese girl, 21 years old, with no particular history, who had multiple sclerosis following a decrease in visual acuity for six months associated with tingling and motor deficit of the lower right limb. Protein electrophoresis and cerebral magnetic resonance imaging (MRI) advocated multiple sclerosis. Conclusion: This observation highlights the fact that multiple sclerosis is a rare condition in black African countries and its discovery must always be considered as a diagnosis of elimination.
\end{abstract}

\section{Subject Areas}

Neurology

\section{Keywords}

Multiple Sclerosis, Gabon

\section{Introduction}

Multiple sclerosis (MS) is a chronic inflammatory disease of the central nervous system, affecting the sheaths of myelin, which is the source of demyelinating plaques [1]. A plaque is a well-defined area in which there is: destruction of myelin, edema, mononuclear cell infiltrate and reactional gliosis [1].

MS is clinically manifested by subacute encephalic and/or medullary arrays

[2]. There is a North-South gradient in the distribution of the disease. Areas of 
high prevalence $(\mathrm{P})$ are described as follows: 650 parallel North: $\mathrm{P}>30 / 100,000$ inhabitants: Scandinavia, Scotland, Northern Europe, Canada and Northern USA [2]. Areas of intermediate prevalence: around 450 parallel North: P between 5 and 30/100,000 inhabitants: Central Europe and Southwest USA. Areas of low prevalence around 20 North parallel: $\mathrm{P}<5 / 100,000$ inhabitants: around the Mediterranean, Mexico [2].

According to one study, prevalence rates of MS are rapidly declining towards the equator. In Black Africa several reviews of the literature confirm the apparent scarcity of MS [2].

Gabon by its strategic position around the equator with the presence of MS among a Gabonese never left the country de facto blows the absence of this affection in black Africa.

The positive diagnosis of MS is based on several arguments [1]:

- The field: young adult.

- The dissemination in space of flare-ups and lesions in cerebral and/or medullary Magnetic Resonance Imaging (MRI).

- The absence of other diseases that explain the neurological disorders.

\section{Observation}

Patient G.A.J, 21 years old girl (File: 121/2018). Gabonese, Miénée ethnic, with no particular antecedent, was hospitalized in neurology at the University Hospital of Libreville for a decrease in visual acuity of brutal installation associated with diffuse headaches, vertigo and tingling of the lower right limb. The neurological examination revealed single-limb lesions of the right lower limb, optic nerve (II) and superficial sensory syndrome.

Sagittal and axial cerebral magnetic resonance imaging (MRI) consisted of diffusion hypersignals and T2 FLAIR of numerous demyelinating lesions in addition and tentorial and right cerebellar condyle in favor of a demyelinating lesion (Figure 1).

Electrophoresis of the proteins in the CSF and in the blood showed a polyclonal increase in gamma globulins with an increase in the alpha 1 globulin fraction; the sedimentation rate was $105 \mathrm{~mm}$ in the first hour and protein-C reactive at $8 \mathrm{mg} / \mathrm{l}$. Immunoassay: anti-nuclear autoantibodies: 80 , native AC-anti-DNA: $<10 \mathrm{IU} / \mathrm{ml}, \mathrm{AC}$-anti-ENA: 0.7 (negative), AC-anti-NMO: negative.

The biological assessment noted: NFS: normal, VS accelerated to $19 \mathrm{~mm} / 1 \mathrm{st} \mathrm{H}$ and $31 \mathrm{~mm} / 2 \mathrm{nd} \mathrm{H}$, glycemia: $4.4 \mathrm{mmol} / \mathrm{l}$, creatinemia: $38 \mu \mathrm{mol} / \mathrm{l}$, urea: 3.6 $\mathrm{mmol} / \mathrm{l}$, ASAT $=23 \mathrm{IU} /$ Land ALAT $=16 \mathrm{UI} / \mathrm{l}$,Calcemia: $2.3 \mathrm{mmol} / \mathrm{l}$, Protein electrophoresis: moderate polyclonal increase, SRV: negative, blood ionogram: normal.

The diagnosis of Multiple Sclerosis (MS) was retained taking into account a bundle of clinical and paraclinical arguments. She was evacuated to Morocco in September 2015 where she received treatment with boluses of corticosteroids. Back in Libreville, she continued to be followed at the Libreville University 


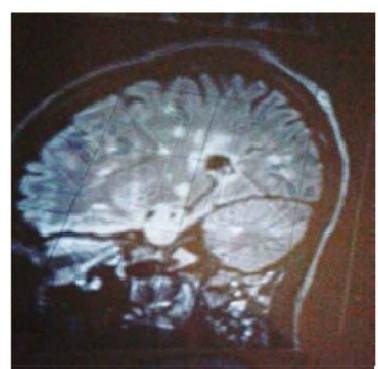

(a)

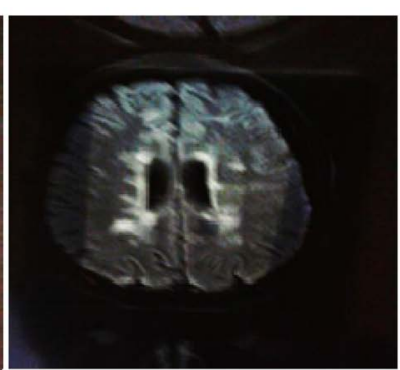

(b)

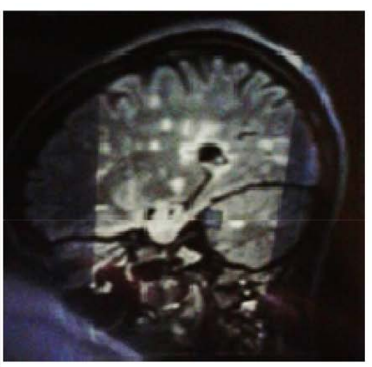

(c)

Figure 1. Sagittal and axial brain MRI showing white matter hypersignals in T2 and T2 Flair sequence (appearance of multiple sclerosis).

Hospital and at the MIA clinic, benefiting from boluses of corticosteroids every three months.

\section{Discussion}

Multiple sclerosis (MS) is an inflammatory disease of the Central Nervous System (CNS). The myelin sheath is the target of the pathological process contrasting with the apparent respect of the axon: it is axon-myelin dissociation. This results in an alteration of the conduction of the nerve impulse explaining the clinical signs. However, if axonal damage can occur secondarily to the myelin destruction, which explains the installation of a permanent handicap, this axonal pain seems to exist in fact from the beginning of the disease, at first subclinically, then by expressing itself permanent disability [3].

The hypothesis of the primary neurodegenerative process associated with a secondary or associated inflammatory response has recently been proposed by some [3]. The precise mechanisms of MS lesions remain poorly understood. The destruction of myelin can involve several mechanisms:

- The first involves predominantly CD8 cytotoxic lymphocytes that attack oligodendrocytes that become Class I MHC-positive Ag during pathological processes;

- The second involves the release of cytotoxic factors, including cytokines, during the inflammatory process. A particular role is given to TNF which, in vitro, is cytotoxic for oligodendrocytes. On the other hand, the fact that TNF also exerts neuroprotective effects makes it difficult to use a therapeutic approach by blocking the molecule;

- The presence of plasma cells, immunoglobulins and complement fractions suggest the destruction of myelin and oligodendrocytes via [3].

MS is considered a rare condition in sub-Saharan Africa, particularly in Central Africa [4]. The case of our patient who has never left Gabon and who presented this condition in the aftermath of headaches associated with tingling and monoparesis of the right lower limb, inevitably revive the discussion on the existence of this condition in Black Africa, especially in Central Africa where no case has been reported in the literature in recent years [4]. So three of these 
questions arise?

1) Has his diagnosis become difficult because the MRI is not yet sufficiently accessible to the population south of the Sahara because of its exorbitant cost? In Gabon, it was in 1990 that the first MRI machine was installed in the private sector and it was only on June 1st 2016 that the CHUL was inaugurated. Gabon currently has only four MRI centers, including one center in a public hospital. Its cost remains relatively high (US \$ 454 for example) and does not allow accessibility to a large number of patients, despite the care of the population by the National Fund for Health Insurance and Social Security (CNAMGS).

2) Is the rarity of this affection due to the existence of a North-South gradient?

In fact, the closer we get to the equator, the more the prevalence of the disease tends to decrease [2] [3] [4]. In tropical and intertropical countries the prevalence of MS varies between 5.0 and 6.7/100,000 inhabitants [2].

3) Are there environmental factors south of the Sahara responsible for the rarity of this disease?

For DIAGANA et al. in 2008, Black Africa's exposure to ultraviolet B (UVB) radiation is one of the key factors in the distribution of MS [2].

Thus for some authors [5] [6], the UVB stimulating the production of vitamin D3 which itself would lead to a modulation of the secretion of melanin from puberty and would be the cause of the distribution of MS in function of race [2].

MS is characterized by its clinical polymorphism. It is manifested by tables of encephalic, medullary or sub-acute encephalomedullary involvement.

Our patient presented a much more encephalic symptomatology revealed by the neurological examination in front of a disabling headache on frontal sinusitis. The clinical picture has evolved to a heaviness of the right lower limb associated with tingling.

Sensory and motor disorders are described in MS, sensory disorders are especially subjective with tingling sensation of runoff, hot or cold; on the other hand motor disorders can be manifested by a single-sidedness as in our patient, sometimes we can also note a paraparesis and more rarely a hemiparesis [1]. During the various consultations, she had a reduction in visual acuity (BAV), optic nerve damage is explained by the fact that during embryogenesis, this cranial nerve is the only one to be derived from a evagination of the floor of the brain. It thus presents a central type of myelination, as well as the posterior chamber of the eye, whereas the anterior chamber derives from the ectoderm [1].

In sub-Saharan Africa, however, care for MS patients has not changed significantly due to unavailability and the exorbitant cost of first-line drugs (long-term treatment for MS), including immunomodulators by interferon beta. Currently in Gabon the treatment is only symptomatic administration of boluses of corticosteroid in three or five days depending on the case.

\section{Conclusion}

MS is still a relatively rare disease in south of the Sahara, and its detection in a country in Central Africa is of particular interest. Technical advances in brain 
MRI have been numerous in recent years, helping to raise awareness of MRI in the early detection of MS in black populations.

\section{Conflicts of Interest}

The authors declare no conflicts of interest regarding the publication of this paper.

\section{References}

[1] Neurology (2012) Multiple Sclerosis, Neurology. Elsevier Masson, Paris', 91-102.

[2] Diagana, M., N'diaye, M., Soumare, O., Aqad, B., OuldBeddi, M. and Preux, P.M. (2008) Multiple sclerosis in Mauritania. African Journal of Neurological Sciences, 27, 47-56. https://doi.org/10.4314/ajns.v27i1.7610

[3] Association of Colleges of Immunology Teachers of French Language Universities (2010-2011) Multiple Sclerosis. Francophone Virtual Medical University, 1-15.

[4] Grunitzky, E.K., Balogou, A.A.K. and Kowou, A.L. (2001) Multiple Sclerosis in Black Africa. African Journal of Neurological Sciences, 20, 4-7. https://doi.org/10.4314/ajns.v20i1.7519

[5] Duquette, P. and Girard, M. (1993) Hormonal Factors in Susceptibility to Multiple SCLEROSIS. Current Opinion in Neurology, 6, 195-201.

[6] Sandyk, R. (1997) Role of the Pineal Gland in Multiple Sclerosis: A Hypothesis. The Journal of Alternative and Complementary Medicine, 3, 297-390. https://doi.org/10.1089/acm.1997.3.267 